\title{
Experience of Octreotide Therapy for Hyperinsulinemic Hypoglycemia in Neonates Born Small for Gestational Age: A Case Series
}

\author{
Sinian Pan Min Zhang Yinya Li \\ Department of Neonatology, Third Affiliated Hospital of Sun Yat-sen University, Guangzhou, China
}

\begin{abstract}
Key Words
Hyperinsulinism · Hypoglycemia · Small for gestational age · Octreotide
\end{abstract}

\begin{abstract}
Aims: Hyperinsulinemic hypoglycemia $(\mathrm{HH})$ is common in small-for-gestational-age (SGA) neonates. Diazoxide is often used as the first-line medication for $\mathrm{HH}$ in SGA neonates. Unfortunately, diazoxide is not authorized in China. We examined the effectiveness of octreotide as an alternative therapy to treat $\mathrm{HH}$ in SGA neonates. There is limited data on the use of octreotide in HH of SGA neonates. Methods: Seven SGA neonates with $\mathrm{HH}$ who were admitted to the Department of Neonatology at the Third Affiliated Hospital of Sun Yat-sen University between January 2013 and December 2014 received octreotide at an initial dose of $5 \mu \mathrm{g} / \mathrm{kg} /$ day through subcutaneous injection at 8-hour intervals. Depending on the glycemic control, the dose of octreotide was increased in increments of $2-5 \mu \mathrm{g} / \mathrm{kg} /$ day every $3-5$ days to the maximum dose of $30 \mu \mathrm{g} / \mathrm{kg} /$ day. Results: The age of neonates with $\mathrm{HH}$ diagnosis ranged from 1 to 4 days. The maximum dose of octreotide ranged from 8 to $18 \mu \mathrm{g} / \mathrm{kg} /$ day. The duration of octreotide therapy ranged from 9 to 45 days. All patients had a clear glycemic response to octreotide, and no major adverse events were observed during the treatment. Conclusions: Octreotide may be a useful alternative therapy in $\mathrm{HH}$ of SGA neonates when diazoxide is unavailable.
\end{abstract}

(c) 2015 S. Karger AG, Basel
(C) 2015 S. Karger AG, Base

$1663-2818 / 15 / 0846-0383 \$ 39.50 / 0$

\section{Introduction}

Small-for-gestational-age (SGA) neonates are defined as neonates whose birth weights are below the 10th percentile for gestational age. SGA neonates are at increased risk of hypoglycemia due to decreased hepatic glycogen stores, higher energy requirements, increased insulin sensitivity and hyperinsulinism $[1,2]$.

Hyperinsulinemic hypoglycemia $(\mathrm{HH})$, a major cause of severe hypoglycemia during the neonatal and infancy period, is characterized by inappropriate insulin secretion from the pancreatic beta cells in the presence of low blood glucose levels [3]. In the newborn and infancy periods, $\mathrm{HH}$ can be either congenital or secondary to certain risk factors. Congenital $\mathrm{HH}$ involves either defects in the genes ABCC8 and KCNJ11 (encoding for the 2 proteins SUR1 and KIR6.2 of the pancreatic $\beta$-cell $\mathrm{K}_{\mathrm{ATP}}$ channel, respectively) or abnormalities in the enzymes glucokinase, glutamate dehydrogenase and short-chain acylCoA dehydrogenase (SCHAD) [4]. Transient $\mathrm{HH}$ may be secondary to certain risk factors (such as maternal diabetes mellitus, prenatal asphyxia and SGA). In 1984, Collins and Leonard [2] first described transient $\mathrm{HH}$ in SGA infants.

Although hyperinsulinism in SGA neonates is not genetic, it resolves spontaneously within the first several months of life. Neonates with severe transient $\mathrm{HH}$ may require intravenous infusion of $>8 \mathrm{mg} / \mathrm{kg} / \mathrm{min}$ glucose to maintain normoglycemia, similar to neonates with per-

\section{KARGER 125}

E-Mail karger@karger.com www.karger.com/hrp
Sinian Pan

Department of Neonatology

Third Affiliated Hospital of Sun Yat-sen University

Guangzhou 510630 (China)

E-Mail pansinian@163.com 
manent (genetic) hyperinsulinism. It is important to identify and treat $\mathrm{HH}$ early and aggressively in this condition in order to prevent adverse neurological outcomes and intellectual impairment [5]. Diazoxide, a $\mathrm{K}_{\mathrm{ATP}}$ channel agonist, is often used as the first-line medication for prolonged $\mathrm{HH}$ [6]. $\mathrm{HH}$ in SGA is responsive to diazoxide $[2,7]$.

Unfortunately, diazoxide cannot enter the Chinese market lawfully. To prevent adverse neurological outcomes and intellectual impairment, we must seek other therapy options to deal with $\mathrm{HH}$ in SGA neonates. Octreotide is the second line of medical therapy for infants with diazoxide-unresponsive congenital $\mathrm{HH}$. We use octreotide as an optional therapy to treat HH in SGA neonates. To our knowledge, there are no known reports on the use of octreotide as first-line drug in the treatment of $\mathrm{HH}$ in SGA neonates. We describe 7 cases of successful treatment with octreotide directly, without the trial use of diazoxide. We propose that octreotide may be a useful optional therapy in $\mathrm{HH}$ of SGA neonates when diazoxide is not available.

\section{Methods}

\section{Patients}

Seven SGA neonates (defined as birth weight $<10$ th percentile for gestational age) with $\mathrm{HH}$ who were admitted to the Department of Neonatology at the Third Affiliated Hospital of Sun Yatsen University between January 2013 and December 2014 participated. Patients were recruited to participate in the study within 24 $\mathrm{h}$ of birth. Neonates with a history of perinatal asphyxia, maternal carbohydrate intolerance, family history of hypoglycemia among siblings, Rhesus isoimmunization and syndromic forms such as Beckwith-Wiedemann syndrome were excluded from the study. All patients met the currently accepted diagnostic criteria for $\mathrm{HH}$ [8]. A central venous catheter was inserted, and high doses of glucose were administered to stabilize blood glucose levels at more than $3.5 \mathrm{mmol} / \mathrm{l}$

\section{Clinical Assays}

All plasma assays were performed at the Clinical Laboratory of the Third Affiliated Hospital of Sun Yat-sen University. Blood was collected at the time of diagnosis and during treatment. Serum glucose was measured by the glucose oxidase method. Insulin was measured by electrochemiluminescence immunoassay (Roche Diagnosis, Basel, Switzerland), and cortisol was determined by chemiluminescence immunoassay (Siemens).

\section{Treatment}

All patients received octreotide (Novartis Pharma Schweiz AG, Basel, Switzerland) at an initial dose of $5 \mu \mathrm{g} / \mathrm{kg} /$ day through subcutaneous injection at 8 -hour intervals. Their response was assessed $48 \mathrm{~h}$ later. The effectiveness of clinical management was defined as blood glucose that can be maintained above $3.5 \mathrm{mmol} / \mathrm{l}$ after a short period of fasting (4 h in neonates) [9]. Depending on the glycemic control, the dose of octreotide was increased in increments of $2-5 \mu \mathrm{g} / \mathrm{kg} /$ day every $3-5$ days to the maximum dose of 30 $\mu \mathrm{g} / \mathrm{kg} /$ day. Once blood glucose levels were stable, the intravenous glucose and the dosage of octreotide were gradually tapered by a decrease of $2-5 \mu \mathrm{g} / \mathrm{kg} /$ day every $3-5$ days to the minimum dose of $5 \mu \mathrm{g} / \mathrm{kg} /$ day. If glucose monitoring indicated no recurrence of hypoglycemia and frequent feeding alone could maintain their glucose above $3.5 \mathrm{mmol} / \mathrm{l}$, octreotide was stopped. For the follow-up study, self-monitoring of blood glucose was required at least 2-4 times every day, and $\mathrm{HbAlc}$ and insulin were measured every 3 months. Growth development was evaluated every month in infants younger than 6 months, every 2 months in infants aged between 6 and 12 months and every 6 months in infants older than 1 year. Brain development was evaluated every 6 months at followup based on the Gesell developmental schedules.

\section{Informed Consent}

Written informed consent for all tests and treatment was obtained from the patient's parent(s) or guardian(s). The study was approved by the Ethics Committee of the Third Affiliated Hospital of Sun Yat-sen University (Approval ID: [2015] 2-139).

\section{Results}

The clinical and laboratory characteristics at diagnosis and the responses to treatment of each of the 7 neonates treated with octreotide are shown in table 1 . Three male and 4 female neonates were recruited to participate in the study. Among them, 6 were preterm neonates, and 1 was a full-term neonate. The gestational age ranged from $33^{+1}$ to $39^{+6}$ weeks. The birth weight ranged from 1,250 to $2,600 \mathrm{~g}$. Asymptomatic hypoglycemia was the most common presenting symptom and was recorded in $6(85.7 \%)$ patients. Hypoglycemic seizure was recorded in 1 (14.3\%) patient. Insulin levels at the time of hypoglycemia ranged from 8.42 to $70.05 \mathrm{mU} / \mathrm{l}$. The insulin/glucose $(\mathrm{mg} / \mathrm{dl}) \mathrm{ra}-$ tio ranged from 7.45 to 37.52 .

Due to the severity of their hypoglycemia, the neonates required a combination of hydrocortisone infusion and intravenous fluids with a high concentration of dextrose to maintain normoglycemia at the initiation of treatment with octreotide, after which a good glycemic response was noted. Accordingly, the doses of dextrose were gradually tapered, and enteral feeding simultaneously increased. The maximum dose of octreotide ranged from 8 to $18 \mu \mathrm{g} /$ $\mathrm{kg} /$ day. Over a period of 9-45 days, each baby maintained stable blood glucose levels without the need for intravenous glucose infusion. Octreotide infusions were then gradually discontinued, since blood glucose levels were stable at more than $3.5 \mathrm{mmol} / \mathrm{l}$. Subsequently, all 7 babies were able to receive all their nutrition enterally. 
Table 1. Clinical and laboratory characteristics at diagnosis and treatment in 7 patients with $\mathrm{HH}$

\begin{tabular}{|c|c|c|c|c|c|c|c|}
\hline & \multicolumn{7}{|l|}{ Patient No. } \\
\hline Gender & male & female & female & female & male & male & female \\
\hline Birth weight, $g$ & 1,500 & 2,050 & 1,800 & 1,250 & 1,550 & 2,600 & 1,800 \\
\hline Gestational age, weeks & 34 & $35^{+1}$ & 34 & $33^{+1}$ & $35^{+1}$ & $39^{+6}$ & $36^{+5}$ \\
\hline Symptom at presentation & asymptomatic & seizure & asymptomatic & asymptomatic & asymptomatic & asymptomatic & asymptomatic \\
\hline Insulin/glucose ratio, mg/dl & 12.78 & 37.52 & 34.00 & 11.57 & 18.31 & 7.45 & 18.37 \\
\hline \multicolumn{8}{|l|}{ Peak intravenous glucose } \\
\hline infusion rate, $\mathrm{mg} / \mathrm{kg} / \mathrm{min}$ & 15 & 17 & 20 & 18 & 15 & 13 & 20 \\
\hline \multicolumn{8}{|l|}{ Maximum dose of octreotide } \\
\hline requirement, $\mu \mathrm{g} / \mathrm{kg} / \mathrm{day}$ & 10 & 10 & 8 & 10 & 15 & 10 & 18 \\
\hline Other treatment & hydrocortisone & hydrocortisone & hydrocortisone & none & hydrocortisone & hydrocortisone & none \\
\hline
\end{tabular}

Glucose: $1 \mathrm{mmol} / \mathrm{l}=18 \mathrm{mg} / \mathrm{dl}$.

The patients did not develop any side effects while receiving octreotide; no gastrointestinal side effects such as abdominal discomfort, diarrhea, transient elevation of liver transaminases, episodes of necrotizing enterocolitis (NEC), gallstones or sludge were observed in our cohort. All patients were followed for 1-2 years. The levels of glucose, $\mathrm{HbA} 1 \mathrm{c}$ and insulin were within normal limits. Normal linear growth and weight were maintained. No mental retardation occurred in these 7 infants.

\section{Discussion}

In our study, hypoglycemia occurred on day 1 of life in 5 neonates. Patients 4 and 6 presented with hypoglycemia on days 3 and 4 of life, respectively. Symptoms of hypoglycemia are mostly nonspecific such as lethargy, poor feeding, apnea, seizures and coma [10]. In our study, asymptomatic hypoglycemia was the most common presenting symptom.

In contrast to children with severe neonatal-onset hyperinsulinism associated with $\mathrm{K}_{\mathrm{ATP}}$ mutations, sequencing of the genes encoding the $\mathrm{K}_{\mathrm{ATP}}$ channel, KCNJ11 and $A B C C 8$, did not identify any mutations in the SGA patients [11]. We did not take a genetic analysis for our study. Although the $\mathrm{HH}$ in SGA neonates can resolve spontaneously, the timing of resolution is variable. In some cases, $\mathrm{HH}$ may persist up to 1 year [7]. These infants have increased glucose requirements and go on having problems with hypoglycemia longer than those hypogly- cemic babies who are not hyperinsulinemic [1]. Early identification, prevention and treatment of hypoglycemia in patients with defects in certain metabolic pathways or in the regulation of insulin secretion are important for long-term outcomes [12]. The initial treatment for hypoglycemia is with glucose and sometimes with steroids. In our study, all patients were given central venous catheters to control the intravenous glucose infusion rate. The peak intravenous glucose infusion rate ranged from 13 to 20 $\mathrm{mg} / \mathrm{kg} / \mathrm{min}$. Five neonates required hydrocortisone infusion to maintain normoglycemia. A high intravenous glucose infusion rate will increase the burden of the heart. Once the diagnosis of hyperinsulinemia is established, a specific treatment of $\mathrm{HH}$ must be initiated [13]. Diazoxide, a $\mathrm{K}_{\mathrm{ATP}}$ channel agonist, remains the first-line therapy in prolonged $\mathrm{HH}$ of SGA neonates. Up until now, according to the reported literature, SGA neonates have all been responsive to diazoxide. Most of these neonates responded to moderate doses of diazoxide, $5-10 \mathrm{mg} / \mathrm{kg} / \mathrm{day}$, though a few needed $15-20 \mathrm{mg} / \mathrm{kg} /$ day. Approximately $20 \%$ were unable to stop taking diazoxide before 6 months of age $[7,11,14]$. The most common adverse effect of diazoxide is hypertrichosis. Another side effect is water retention, which could cause serious problems such as congestive heart failure or the reopening of the ductus arteriosus $[15,16]$. These heart and vascular complications are mostly observed in preterm children, raising the question of its contraindication in premature patients. In our study, 6 were preterm neonates. It seems that diazoxide is not suitable to treat $\mathrm{HH}$ in these neonates. 
Unfortunately, diazoxide cannot enter the Chinese market lawfully. To prevent adverse neurological outcomes and intellectual impairment, we use octreotide as an optional therapy to treat HH in SGA neonates. Octreotide, an analog of the natural hormone somatostatin, which has inhibitory effects on the release of insulin from pancreatic $\beta$-cells through a different mechanism, is commonly used in congenital hyperinsulinism patients as a second-line medication $[3,13,17]$. It inhibits insulin secretion distal to the $\mathrm{K}_{\mathrm{ATP}}$ channel by inducing hyperpolarization of $\beta$-cells and directly inhibiting the voltagedependent calcium channel. To our knowledge, no cases have been published reporting the use of octreotide as first-line therapy in SGA neonates. Our patients had good glycemic control while receiving octreotide. Octreotide therapy enabled us to discontinue intravenous infusions of glucose in all 7 patients. The duration of octreotide therapy ranged from 9 to 45 days, which was much shorter than the treatment time for children with congenital hyperinsulinism [18].

The common adverse effects of octreotide therapy include gastrointestinal symptoms, white stool, a dilated gall bladder with or without gall stones, and growth deceleration after 2 years of age [19]. Rarer but more serious side effects include hepatitis [20], NEC [21] and long QT syndrome [22]. NEC is a devastating gastrointestinal disease among neonates with high morbidity and mortality [23]. Preterm infants born small for gestational age are at a particularly high risk for developing NEC [24, 25]. A substantial reduction in the arterial blood flow of the celiac, superior mesenteric and inferior mesenteric arteries during octreotide treatment is thought to be directly implicated in the pathophysiology of NEC [21]. In our study group, there is a concern that the combination of being preterm, having intrauterine growth restriction (IUGR) and being treated with octreotide has a very high risk of developing NEC. We tried many interventions to prevent
NEC, which included probiotics, minimal enteral nutrition, slow increment in enteral feeds, prolonged fasting and promoting breast milk usage in very-low-birthweight nenonates. In our study, there were no apparent major adverse events. It seems that octreotide therapy for a short duration is relatively safe.

In summary, there is no data on the use of octreotide as a first-line therapy in HH of SGA neonates. The 7 cases of neonatal hyperinsulinism reported here have each been successfully managed with octreotide, and the treatment has been well tolerated. All of the cases demonstrated an excellent response to octreotide, achieving euglycemia, making it a useful option as first-line therapy in $\mathrm{HH}$ of SGA neonates when diazoxide is not available. However, more patients and a longer duration of follow-up should be analyzed to observe the efficacy and safety of octreotide in treating HH in SGA neonates. The association between octreotide and NEC should be noted. We would like to emphasize that neonates receiving octreotide should be closely monitored for signs of NEC (significant abdominal distension, vomiting and feeding intolerance), particularly preterm and IUGR neonates. Compared to the heart and vascular complications caused by diazoxide in preterm babies, NEC caused by octreotide is more severe and harmful. We suggest that octreotide should be used in preterm/IUGR babies only if diazoxide is not available.

\section{Acknowledgements}

We thank the staff members of this trial, our colleagues and all the study staff for their enormous efforts in collecting and ensuring the accuracy and completeness of all the data.

\section{Disclosure Statement}

The authors declare that they have no competing interests.

\section{References}

1 Collins JE, Leonard JV, Teale D, Marks V, Williams DM, Kennedy CR, Hall MA: Hyperinsulinaemic hypoglycaemia in small for dates babies. Arch Dis Child 1990;65:1118-1120.

2 Collins JE, Leonard JV: Hyperinsulinism in asphyxiated and small-for-dates infants with hypoglycaemia. Lancet 1984;2:311-313.

-3 Senniappan S, Shanti B, James C, Hussain K: Hyperinsulinaemic hypoglycaemia: genetic mechanisms, diagnosis and management. J Inherit Metab Dis 2012;35:589-601.
4 Arya VB, Mohammed Z, Blankenstein O, De Lonlay P, Hussain K: Hyperinsulinaemic hypoglycaemia. Horm Metab Res 2014;46:157-170.

$\checkmark 5$ Kapoor RR, James C, Hussain K: Advances in the diagnosis and management of hyperinsulinemic hypoglycemia. Nat Clin Pract Endocrinol Metab 2009;5:101-112.

-6 Senniappan S, Arya VB, Hussain K: The molecular mechanisms, diagnosis and management of congenital hyperinsulinism. Indian J Endocrinol Metab 2013;17:19-30.
7 Hoe FM, Thornton PS, Wanner LA, Steinkrauss L, Simmons RA, Stanley CA: Clinical features and insulin regulation in infants with a syndrome of prolonged neonatal hyperinsulinism. J Pediatr 2006;148:207-212.

$>8$ Agladioglu SY, Savas Erdeve S, Cetinkaya S, Bas VN, Peltek Kendirci HN, Onder A, Aycan Z: Hyperinsulinemic hypoglycemia: experience in a series of 17 cases. J Clin Res Pediatr Endocrinol 2013;5:150-155. 
9 Kapoor RR, Flanagan SE, Arya VB, Shield JP, Ellard S, Hussain K: Clinical and molecular characterisation of 300 patients with congenital hyperinsulinism. Eur J Endocrinol 2013; 168:557-564.

10 Meissner T, Wendel U, Burgard P, Schaetzle S, Mayatepek E: Long-term follow-up of 114 patients with congenital hyperinsulinism. Eur J Endocrinol 2003;149:43-51.

11 Arya VB, Flanagan SE, Kumaran A, Shield JP, Ellard S, Hussain K, Kapoor RR: Clinical and molecular characterisation of hyperinsulinaemic hypoglycaemia in infants born small-forgestational age. Arch Dis Child Fetal Neonatal Ed 2013;98:F356-F358.

$>12$ Fong CY, Harvey AS: Variable outcome for epilepsy after neonatal hypoglycaemia. Dev Med Child Neurol 2014;56:1093-1099.

13 Arnoux JB, Verkarre V, Saint-Martin C, Montravers F, Brassier A, Valayannopoulos V, Brunelle F, Fournet JC, Robert JJ, Aigrain Y, Bellanne-Chantelot C, de Lonlay P: Congenital hyperinsulinism: current trends in diagnosis and therapy. Orphanet J Rare Dis 2011;6:63.

14 Fafoula O, Alkhayyat H, Hussain K: Prolonged hyperinsulinaemic hypoglycaemia in newborns with intrauterine growth retardation. Arch Dis Child Fetal Neonatal Ed 2006; 91:F467.
5 Demirel F, Unal S, Cetin II, Esen I, Arasli A: Pulmonary hypertension and reopening of the ductus arteriosus in an infant treated with diazoxide. J Pediatr Endocrinol Metab 2011; 24:603-605.

16 Yoshida K, Kawai M, Marumo C, Kanazawa H, Matsukura T, Kusuda S, Yorifuji T, Heike T: High prevalence of severe circulatory complications with diazoxide in premature infants. Neonatology 2014;105:166-171.

17 Demirbilek H, Shah P, Arya VB, Hinchey L, Flanagan SE, Ellard S, Hussain K: Long-term follow-up of children with congenital hyper insulinism on octreotide therapy. J Clin Endocrinol Metab 2014;99:3660-3667.

8 Yorifuji T, Kawakita R, Hosokawa Y, Fujimaru R, Matsubara K, Aizu K, Suzuki S, Nagasaka $H$, Nishibori $H$, Masue M: Efficacy and safety of long-term, continuous subcutaneous octreotide infusion for patients with different subtypes of KATP-channel hyperinsulinism. Clin Endocrinol (Oxf) 2013;78:891897.

19 Yorifuji T: Congenital hyperinsulinism: current status and future perspectives. Ann Pediatr Endocrinol Metab 2014;19:57-68.

20 Koren I, Riskin A, Barthlen W, Gillis D: Hepatitis in an infant treated with octreotide for congenital hyperinsulinism. J Pediatr Endocrinol Metab 2013;26:183-185.
21 Laje P, Halaby L, Adzick NS, Stanley CA: Necrotizing enterocolitis in neonates receiving octreotide for the management of congenital hyperinsulinism. Pediatr Diabetes 2010;11: 142-147.

22 Celik N, Cinaz P, Emeksiz HC, Hussain K, Camurdan O, Bideci A, Doger E, Yuce O, Turkyilmaz Z, Oguz AD: Octreotide-induced long QT syndrome in a child with congenital hyperinsulinemia and a novel missense mutation (p.Met115Val) in the ABCC8 gene. Horm Res Paediatr 2013;80:299-303.

23 Kasivajjula H, Maheshwari A: Pathophysiology and current management of necrotizing enterocolitis. Indian J Pediatr 2014;81:489497.

24 Garite TJ, Clark R, Thorp JA: Intrauterine growth restriction increases morbidity and mortality among premature neonates. Am J Obstet Gynecol 2004;191:481-487.

-25 Olischar M, Messerschmidt A, Repa A, Klebermasz-Schrehof $\mathrm{K}$, Weber $\mathrm{M}$, Leitich $\mathrm{H}$ : The early prediction of neonatal morbidity and mortality in singleton small for gestational age infants with a birthweight $<1,500 \mathrm{~g}$. Wien Klin Wochenschr 2013;125:386-392. 